\title{
The internal oral morphology of some anuran larvae from south India: a scanning electron microscopic study
}

\section{Indrancil Das 1}

Animal Ecology Research Group, Department of Zoology. University of Oxford, South Parks Road, Oxford OXI 3PS, UK

1 Present address: Centre for Herpetology, Madras Crocodile Bank 'Irust, Post Bag 4, Mamallapuram, 'I'amil Nadu 603 104, India

\begin{abstract}
The internat oral morphology of the larvae of four species of sympatric anuman amphibians from a locality in south India was examined by scanning electron microscopy. A close fit between diet and oral structures was found. The mouthparts are considerated as adaptive for a variety of feeding modes, including fllter-feeding, algal-scraping and macrophyte-snipping.
\end{abstract}

\section{Introduction}

The larvae of a great many anuran amphibians are suspension-feeders which produce a current by the pulsed depressions of the buccal floor to draw in food particles that are filtered at various sites inside the oral cavity (review: Sanderson and Wassersug, 1990). The principle organ for creating suspensions, by either snipping macrophytes or scraping algae is the buccal rasp, comprising a pair of horny jaws, labial teeth and soft papillae surrounding the opening of the oral cavity. However, filter-feeding forms (c.g. the larvae of the microhylids; see Parker, 1934) lack keratinised structures. Eight species of anuran amphibians occur sympatrically at Chengai Anna District, Tamil Nadu State, south India. Ficldwork was conducted on the ccology of the larvae and metamorphosed individuals of these eight species (including Rana hexadactyla, R. crassa, R. cyanophlyctis, Tomopterna rolandae, Polypedates maculatus, Uperodon systoma, Microhyla rubra and $M$. ornata). In this communication, I deal solely with the premetamorphic (larval) stages, examining the oral morphology and diet. No larvae of $U$. systoma, $P$. maculatus and $M$. ornata were found, and only a single specimen of $T$. rolandae was collected.

\section{Material and methods}

Tadpoles were collected with dip-nets from a variety of small and large waterbodies and preserved within an hour of capture in a $4 \%$ solution of formaldehyde. Tadpoles 